\title{
OPERATION CHARACTERISTICS OF VARIABLE RELUCTANCE MOTOR SUPPLIED WITH BIPOLAR CURRENT
}

\author{
M. A. Shanab, M. M. Khater and A. H. Morsi \\ Department of Electrical Engineering, Faculty of Engineering, \\ Minoufiya University, Shebin El-Kom, Egypt
}

\begin{abstract}
Switched reluctance motor is one of the most recently developed electrical motors which is characterized by its simplicity, ruggedness and flexibility of its operating characteristics. In spite of these it suffers from torque pulsations and the lack of a standard power electronic converter due to its uni-polar current excitation pulses. This paper introduces an alternative variable reluctance motor with fully-pitched winding and bipolar excitation which can be supplied by a standard power electronic switch module and has a ripple-free torque. Throughout the present work a mathematical model for the proposed motor type is developed and investigated by computer simulation. The operating characteristics for this type are presented along with those of the conventional switched reluctance motor, which emphasis the better performance of the proposed motor type.

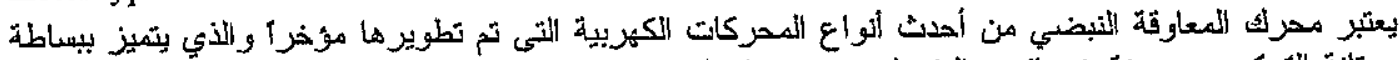

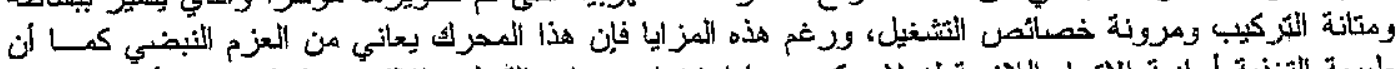

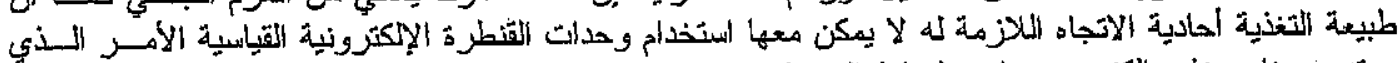

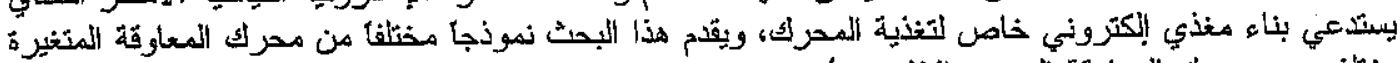

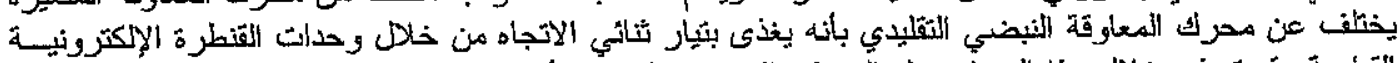

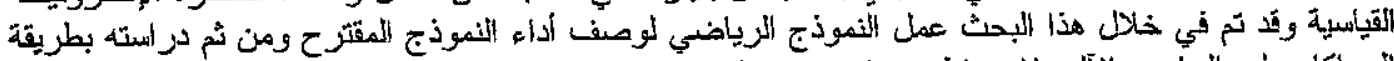

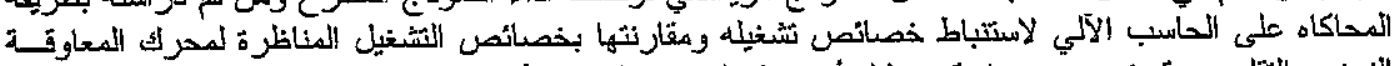

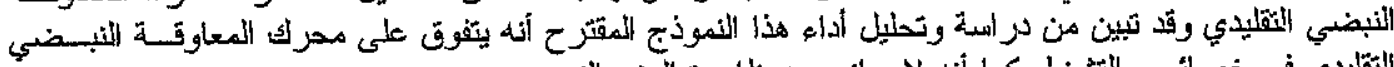

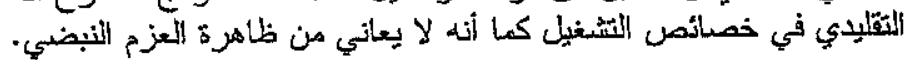

Keywords: Switched Reluctance Motor - Fully Pitched Winding - Bipolar Excitation

\section{INTRODUCTION}

Doubly salient switched reluctance motors (SRM) have received increasing attention over the past decades, with a large number of publications reviewing their relevant merits with regard to other machine types [1]. This type of reluctance machines usually has a short-pitch single-tooth windings supplied from uni-polar converters and derives its torque due to changes in their phase self inductances. Despite of the simplicity of this motor type, it is characterized by its poor utilization of both electric and magnetic circuits. This drawback is basically, due to the introduction of a magnetic gearing ratio, which arises from the doubly salient structure. The magnetic circuit of this motor type is poorly utilized due to intermittent phase excitation to coincide positive sloped periods of its varying self inductance. Poor utilization of electric circuits arises directly from short pitching of motor windings. This arrangement results a complete decoupling between phases, so that the magneto-motive force (MMF) driving magnetic flux down any one stator tooth must be supplied entirely from a single phase of the machine [2]. In contrast, the net MMF in a typical sinusoidally excited AC machine is 1.5 times the peak phase MMF.

Conventional SRM has another difficulty regarding its power converter. It is usually energized by a unipolar power converter with positive current pulses enforced successively through its phase windings. Despite its simplicity, the phase winding has to be embedded in series between two electronic switches, rather than to be connected to the mid-point like standard ac bridge converter circuits. This specific way of winding connection results an increased power semiconductor costs, simply because its different power converter topology compared to all other brushless variable speed drives [3].

From the previous discussion, it is clear that winding configuration and excitation schemes of SRM have a great influence on the drive cost, machine utilization and its developed torque. Some attempts have been reported in literature to develop alternative types of SRM provided with fully-pitched stator windings spanning several stator teeth and energized with different excitation schemes $[2,4-8]$. 
The power conversion and torque production in fullypitched SRM are somewhat different than conventional SRM. While single-tooth winding SRM derives its torque solely from changes in phase self inductance, in fully-pitched SRM mutual inductance contributes in the developed torque as well. In some designs, self inductance becomes constant and the whole torque is derived solely from mutual inductances $[9,10]$.

A doubly-salient fully-pitched SRM with different excitation patterns has been introduced $[2,5]$. It has been found that it derives higher torque than conventionally wound SRM [11]. Excitation patterns and power converter requirements for that type are studied [7]. Flux-linkage control of fully-pitched SRM connected in delta to a standard three-phase bridge inverter has been introduced [8]. The control principle is explained and practical flux-linkage and current waveforms are shown [6]. In all these designs modification is restricted to the winding configuration, while the doubly-salient structure is preserved.

It is well known that the doubly-salient structure is the origin of torque ripple and acoustic noise associated with conventional SRM. An attempt has been introduced to reduce these drawbacks by choosing the best dimensions of both stator and rotor pole tip shape [12] under maintaining the doublysalient nature. Other attempts have been reported to alter this doubly-salient structure to reduce torque ripple and acoustic noise in this machine $[4,13]$. A singly-salient fully-pitched SRM with uni-polar excitation has been introduced $[4,13]$, however, energizing this type with uni-polar excitation pattern was found to be inferior to the doubly-salient one.

This paper introduces an alternative type of SRM with fully-pitched winding and bipolar excitation. The proposed motor configuration is a variable reluctance motor (VRM) consists of a cylindrical stator provided with a typical four-pole, three-phase distributed ac winding. The rotor is a salient member consists of four-pole single-stack steel laminations without any winding. This stator is excited by a variable frequency inverter clocked and synchronized with a rotor position sensor mounted to the rotor shaft as shown in Fig. 1. The variable frequency inverter of the proposed system provides the motor with three-phase bipolar excitation, which in turn establishes a rotating MMF around the stator circumference. The rotor position sensor provides synchronization and locking between rotor saliencies and rotating MMF pole pattern established in the stator side. The use of rotor position feedback distinguishes the proposed motor drive configuration from the synchronous reluctance motor. Due to the rotor position feedback the proposed system is inherently a variable speed drive. The operating speed is always determined by equilibrium between developed torque and load torque.

In this paper a mathematical model for the proposed three-phase bipolar-excited VRM is developed and implemented in a simulation program to predict its performance characteristics at different impressed voltages. These characteristics are compared with those of the conventional uni-polar SRM to evaluate its merits.

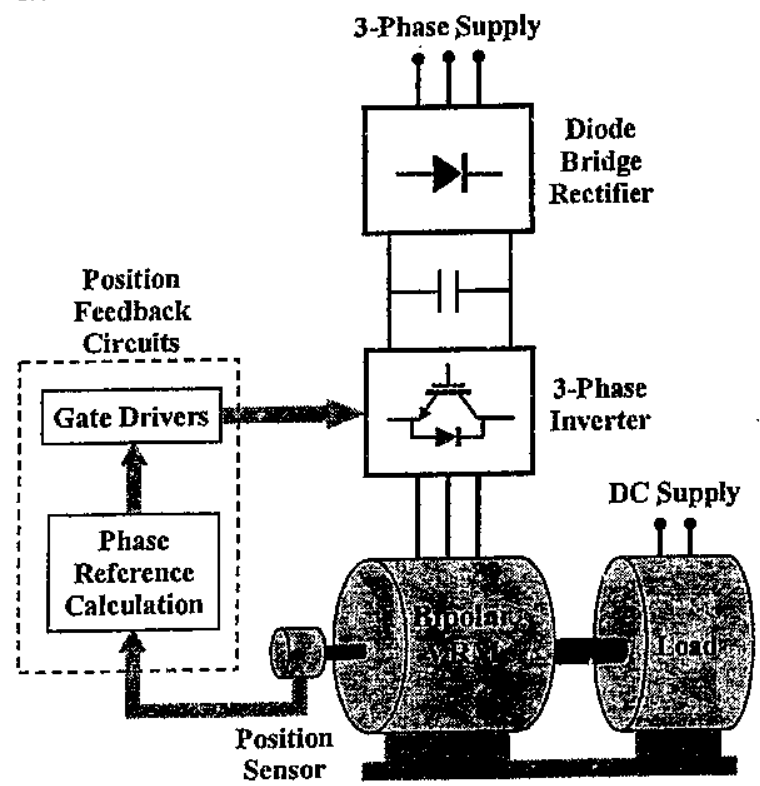

Fig. 1. Schematic diagram of the proposed bipolar variable reluctance motor drive system.

\section{MATHEMATICAL ANALYSIS}

Mathematical analysis for both uni-polar excited doubly-salient SRM and the proposed bipolar-excited VRM are introduced here to facilitate a comparison between their operating performances.

\subsection{Mathematical Model of SRM}

The voltage applied to any phase $\mathrm{k}$ at the rotor position $\theta_{\mathrm{k}}$ can be expressed as [4];

$V_{\dot{k}}\left(\theta_{k}\right)=R_{k} i_{k}+\frac{d \psi_{k}\left(\theta_{k}, i_{k}\right)}{d t} \quad k=1,2,3$

where $R$ is the phase resistance, $V_{k}\left(\theta_{k}\right)$ is the voltage applied to the phase winding $\mathrm{k}$ by the power electronic converter and is expressed as follows

$\mathrm{V}_{\mathrm{k}}\left(\theta_{\mathrm{k}}\right)=\left\{\begin{array}{cc}+\mathrm{V}_{\mathrm{dc}} & \theta_{\text {on }} \leq \theta_{\mathrm{k}} \leq \theta_{\text {off }} \\ -\mathrm{V}_{\mathrm{dc}} & \theta_{\text {off }} \leq \theta_{\mathrm{k}} \leq \theta_{\text {ext }} \\ 0 & \theta_{\mathrm{k}}>\theta_{\text {ext }}\end{array}\right.$

where $\theta_{\mathrm{k}}=\theta+(\mathrm{k}-1) . \delta, \theta=\omega \mathrm{t}$ and the step angle is given by; $\delta=2 \pi / \mathrm{qN}_{\text {, }}$

The performance of SRM can be obtained using the family of flux linkage-current curves $\psi(\theta, \mathrm{i})$ at different rotor positions. These curves are rearranged 
and stored in the form of $i(\theta, \psi)$ look-up tables. Using a time stepping numerical integration procedure applied to Eqn (1), the flux linkage of each plase is obtained. At each integration step the phase current is obtained with the aid of the stored $\mathrm{i}(\theta, \psi)$ data. The developed torque is also obtained by a time stepping procedure. For each step the phase co-energy is obtained by numerical integration of the $\psi(\theta, \mathrm{i})$ with respect to phase current:

$\mathrm{W}_{\mathrm{k}}\left(\theta_{\mathrm{k}}, \mathrm{i}_{\mathrm{k}}\right)=\int_{0}^{\mathrm{i}} \psi_{\mathrm{k}}\left(\theta_{\mathrm{k}}, \mathrm{i}_{\mathrm{k}}\right) \mathrm{di} \mathrm{i}_{\mathrm{k}}$

From which the developed torque can be obtained by numerical differentiation of the $\mathrm{W}(\theta, \mathrm{i}) \cdot$ with respect to the corresponding rotor position $\theta_{\mathrm{k}}$

$\mathrm{T}_{\mathrm{k}}\left(\theta_{\mathrm{k}}, \mathrm{i}_{\mathrm{k}}\right)=\frac{\partial \mathrm{W}_{\mathrm{k}}\left(\theta_{\mathrm{k}}, \mathrm{i}_{\mathrm{k}}\right)}{\partial \theta_{\mathrm{k}}}$

The total developed torque is obtained as the summation of the instantaneous torque developed by all phases.

$$
T=\sum_{k=1}^{q} T_{k}\left(\theta_{k}, i_{k}\right)
$$

\subsection{Mathematical Model of Bipolar Excited VRM}

The voltage equation of the three-phase bipolarexcited VRM can be written as;

$[\mathrm{V}]=[\mathrm{R}][\mathrm{i}]+\mathrm{p}[\lambda]$

$[\lambda]=[\mathrm{L}][\mathrm{i}]$

$$
\text { Where } \begin{aligned}
& {[i]=\left[\begin{array}{lll}
i_{a} & i_{b} & i_{c}
\end{array}\right]^{T} } \\
& {[\lambda]=\left[\begin{array}{lll}
\lambda_{a} & \lambda_{b} & \lambda_{c}
\end{array}\right]^{T} } \\
& {[R]=\operatorname{diag}\left[R_{a}, R_{b}, R_{c}\right] } \\
& p=\frac{d}{d t} \\
& {[L]=\left[\begin{array}{ccc}
L_{a} & M_{a b} & M_{a c} \\
M_{b a} & L_{b} & M_{b c} \\
M_{c a} & M_{c b} & L_{c}
\end{array}\right] }
\end{aligned}
$$

Multiplying both sides of Eq.(6) by the phase currents [i] to obtain the instantaneous power drawn from the power mains

$$
[\mathrm{i}]^{\mathrm{T}}[\mathrm{V}]=[\mathrm{i}]^{\mathrm{T}}[\mathrm{R}][\mathrm{i}]+[\mathrm{i}]^{\mathrm{T}} \mathrm{p}\{[\mathrm{L}][\mathrm{i}]\}
$$

The first term of this equation represents the power consumed by copper loss of the phase windings which may be rewritten as;

$$
P_{c u}=[i]^{T}[R][i]=R_{a} i_{a}^{2}+R_{b} i_{b}^{2}+R_{c} i_{c}^{2}
$$

The second term of $\mathrm{Eq} .(8)$ represents the power manipulated by the magnetic field which may be rewritten as;

$\mathrm{P}_{\mathrm{f}}=[\mathrm{i}]^{\mathrm{T}} \mathrm{p}\{[\mathrm{L}][\mathrm{i}]\}$

$$
\begin{aligned}
P_{f}= & p\left(\frac{1}{2} L_{a} i_{a}^{2}+\frac{1}{2} L_{b} i_{b}^{2}+\frac{1}{2} L_{c} i_{c}^{2}+\right. \\
& \left.M_{a b} i_{a} i_{b}+M_{a c} i_{a} i_{c}+M_{b c} i_{b} i_{c}\right)+ \\
& \left(\frac{1}{2} i_{a}^{2} \frac{d L_{a}}{d \theta}+\frac{1}{2} i_{b}^{2} \frac{d L_{b}}{d \theta}+\frac{1}{2} i_{c}^{2} \frac{d L_{c}}{d \theta}+\right. \\
& \left.i_{a} i_{b} \frac{d M_{a b}}{d \theta}+i_{a} i_{c} \frac{d M_{a c}}{d \theta}+i_{b} i_{c} \frac{d M_{b c}}{d \theta}\right) \omega
\end{aligned}
$$

Where $\theta$ is rotor position angle in electrical radians and $\omega=\mathrm{d} \theta / \mathrm{dt}$ is the rotor speed in electrical radians per second.

The field power in turn is divided into two components, the first is power used to change the field energy while the second represents the power converted to mechanical. Accordingly, the torque developed by the machine may be expressed as;

$$
\begin{aligned}
\mathrm{T}_{\mathrm{em}}= & \frac{1}{2} \mathrm{i}_{\mathrm{a}}^{2} \frac{\mathrm{dL}}{\mathrm{d} \theta}+\frac{1}{2} \mathrm{i}_{\mathrm{b}}^{2} \frac{d L_{b}}{d \theta}+\frac{1}{2} \mathrm{i}_{\mathrm{c}}^{2} \frac{d L_{c}}{d \theta}+ \\
& \mathrm{i}_{\mathrm{a}} \mathrm{i}_{\mathrm{b}} \frac{\mathrm{dM} \mathrm{ab}_{\mathrm{ab}}}{\mathrm{d} \theta}+\mathrm{i}_{\mathrm{a}} \mathrm{i}_{\mathrm{c}} \frac{\mathrm{dM} \mathrm{ac}}{\mathrm{d} \theta}+\mathrm{i}_{\mathrm{b}} \mathrm{i}_{\mathrm{c}} \frac{d M_{\mathrm{bc}}}{\mathrm{d} \theta}
\end{aligned}
$$

Self inductances $L_{a}, L_{b}, L_{c}$ and mutual inductances $M_{a b}, M_{b c}, M_{a c}$ are periodic functions of the rotor angle $\theta$. They can be expressed as [14];

Self inductances are;

$\mathrm{L}_{\mathrm{a}}=\mathrm{L}_{\mathrm{a} 0}+\mathrm{L}_{\mathrm{g} 2} \cos 2 \theta$

$\mathrm{L}_{\mathrm{b}}=\mathrm{L}_{\mathrm{b} 0}+\mathrm{L}_{\mathrm{g} 2} \cos \left(2 \theta+120^{\circ}\right)$

$\mathrm{L}_{\mathrm{c}}=\mathrm{L}_{\mathrm{c} 0}+\mathrm{L}_{\mathrm{g}^{2}} \cos \left(2 \theta-120^{\circ}\right)$

Mutual inductances

$$
\begin{aligned}
& \mathrm{M}_{\mathrm{ab}}=\mathrm{M}_{\mathrm{ba}}=-0.5 \mathrm{~L}_{\mathrm{g} 0}+\mathrm{L}_{\mathrm{g} 2} \cos \left(2 \theta-120^{\circ}\right) \\
& \mathrm{M}_{\mathrm{bc}}=\mathrm{M}_{\mathrm{cb}}=-0.5 \mathrm{~L}_{\mathrm{g} 0}+\mathrm{L}_{\mathrm{g} 2} \cos 2 \theta \\
& \mathrm{M}_{\mathrm{ca}}=\mathrm{M}_{\mathrm{ac}}=-0.5 \mathrm{~L}_{\mathrm{g} 0}+\mathrm{L}_{\mathrm{g} 2} \cos \left(2 \theta+120^{\circ}\right)
\end{aligned}
$$

Where:

$\mathrm{L}_{\mathrm{a} 0}=\mathrm{L}_{\mathrm{a} c}+\mathrm{L}_{\mathrm{g} 0}, \mathrm{~L}_{\mathrm{b} 0}=\mathrm{L}_{\mathrm{b} \ell}+\mathrm{L}_{\mathrm{g} 0}, \mathrm{~L}_{\mathrm{c} 0}=\mathrm{L}_{\mathrm{c} \ell}+\mathrm{L}_{\mathrm{g} 0}$

$\mathrm{L}_{\mathrm{a} \ell}, \mathrm{L}_{\mathrm{b} \ell}$ and $\mathrm{L}_{\mathrm{c} \ell}$ Leakage inductances of phases $\mathrm{a}, \mathrm{b}$ and $\mathrm{c}$ respectively.

$\mathrm{L}_{\mathrm{g} 0}=\frac{\mathrm{L}_{\max }+\mathrm{L}_{\min }}{2}, \quad \mathrm{~L}_{\mathrm{g} 2}=\frac{\mathrm{L}_{\max }-\mathrm{L}_{\min }}{2}$

$\mathrm{L}_{\max }$ Maximum phase self inductance at its aligned position.

$\mathrm{L}_{\min }$ Minimum phase self inductance at its unaligned position.

The introduced mathematical models of both unipolar excited doubly-salient SRM and the proposed bipolar-excited VRM are implemented in simulation programs using general purpose simulation program software Matlab/Simulink. The purpose is to predict their operating performance and compare between them to evaluate the proposed motor configuration. 


\section{SIMULATION RESULTS AND DISCUSSION}

A simulation program has been built based on the proposed mathematical model in Matlab/Simulik environment and operated to study the operating performance of both conventional doubly-salient switched reluctance motor and bi-polar excited fullypitched motor. The study covered the developed torque, input current, torque per current, input power, developed mechanical power and copper losses each as a function of the motor speed. These characteristics are studied at different impressed voltages from $10 \%$ to $100 \%$ of the motor rating. A comparison is also held between the operating performances of the two motors at different applied voltages.

The torque-speed characteristics for the two motors are predicted at different impressed voltages from $10 \%$ to $100 \%$ of the motor rating as shown in Fig. 2 . Both motor types have reassembled the torque-speed characteristics of the dc series motor, however they have some differences. While doubly-salient motor has moderate rate of torque decrease with speed, the bi-polar one has a sharp decrease with high torque at low speeds.

A comparison between torque-speed characteristics for the two motors at $50 \%$ and $100 \%$ of their voltage rating as shown in Fig. 3. It is observed that bi-polar excited motor develops higher torque at all operating speeds especially at low speed range.

The higher torque obtained by bi-polar excited motor is explained by its better winding utilization. While doubly-excited motor develops successive torque stroke pulses corresponding to its phase excitation cycle, the whole windings of bi-polar motor are always excited and contribute to the developed torque.

The rms current as a function of the motor speed for the two motors are predicted at different impressed voltages as shown in Fig. 4. Both motor types have a comparable family of current-speed curves which is characterized by high current at low speeds and low current at high speeds. This current variation is due to the variation of the winding back emf in response to the operating speed. At low speeds there is a small back emf which gets higher with the increase of motor speed.

A comparison between the current-speed characteristics for the two motors at $50 \%$ and $100 \%$ of their voltage rating as shown in Fig. 5. It is observed that bi-polar excited motor develops higher current at all operating speeds; however the difference diminishes in the mid-speed range when the rated voltage is impressed on the motor.

The torque per current capability of the motor is considered a useful judge for any benefit could be obtained from the proposed motor configuration. This motor capability is investigated for both motor types as shown in Fig. 6. A comparison is held between the two motor types at $50 \%$ and $100 \%$ of their voltage rating as shown in Fig. 7. It is observed that bi-polar excited motor has a superior torque per current ratio low speeds up to an operating speed around motor base speed. At high speeds the conventional motor has a better ratio.

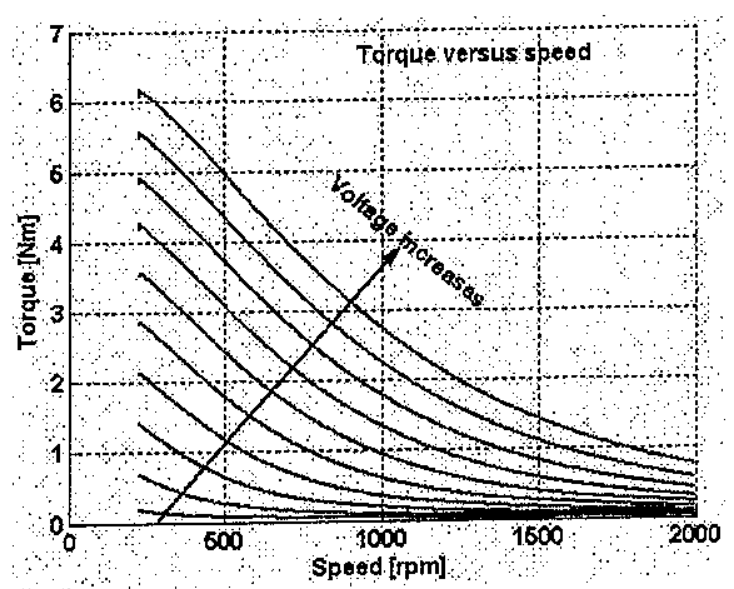

(a) Doubly-salient SRM

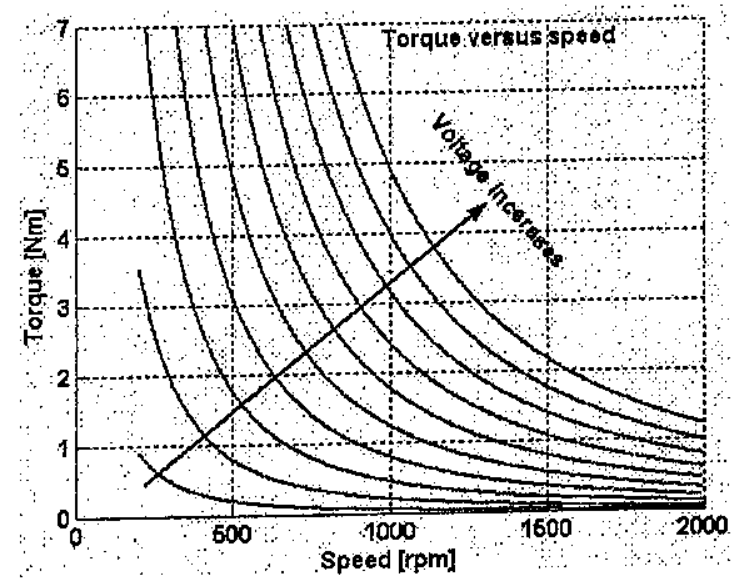

(b) FPSRM

Fig. 2. Torque-speed characteristics for different leveis of supply voltage. 
M. A. Shanab, M. M. Khater and A. H. Morsi, "Operation Characteristics of Variable Reluctance Motor ... "

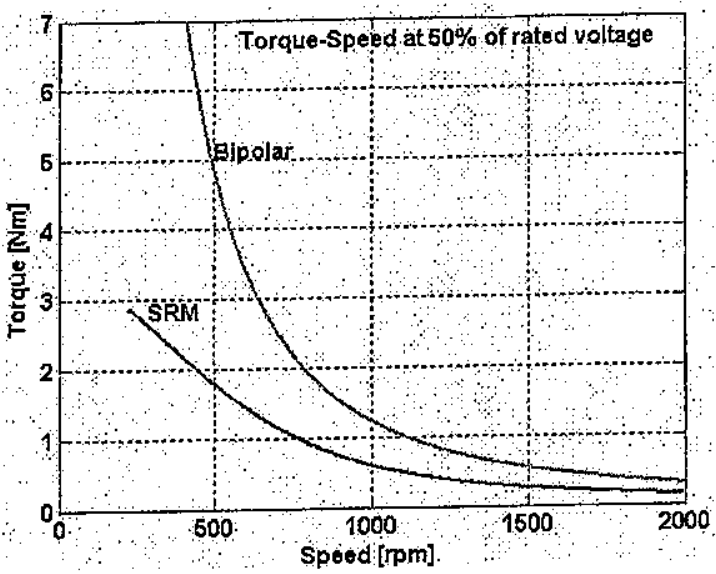

(a) At $50 \%$ of the rated voltage.

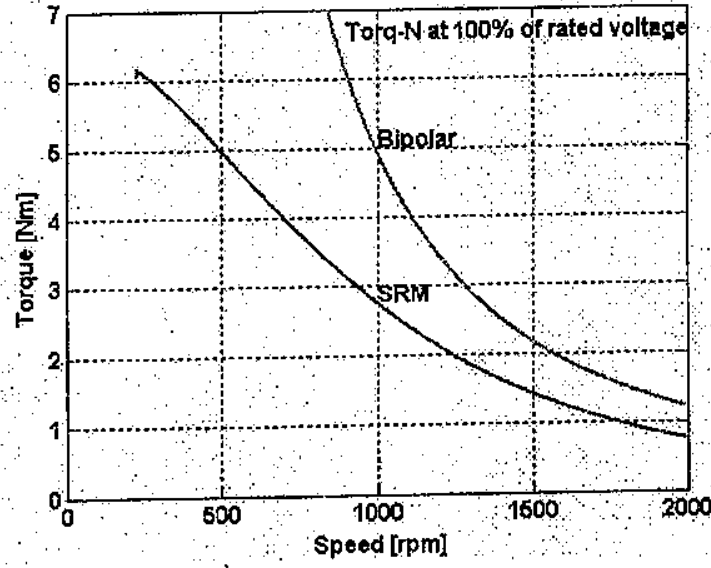

(b) At $100 \%$ of the rated voltage.

Fig. 3. Comparison of torque-speed characteristics for two different levels of supply voltage.

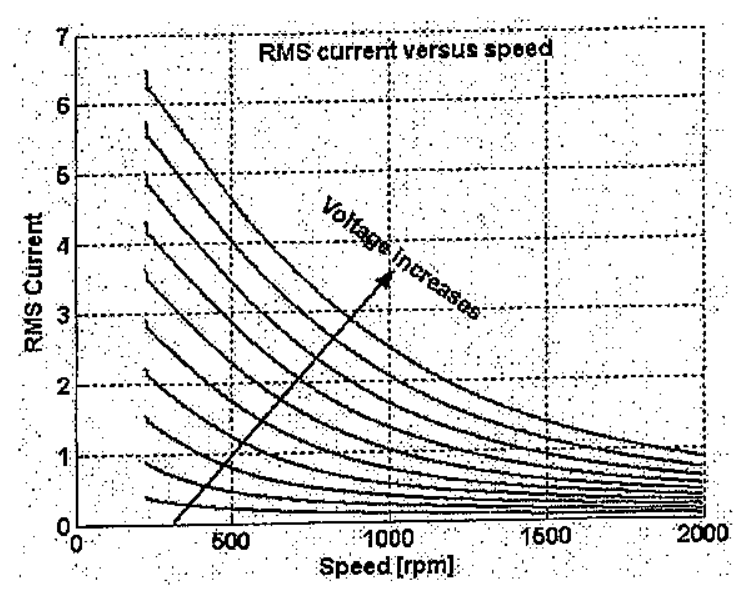

(a) Doubly-salient SRM

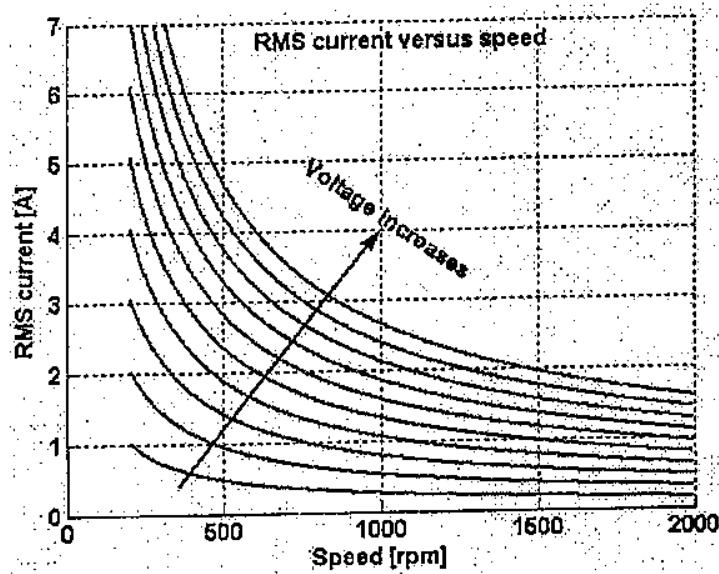

(b) FPSRM

Fig. 4. Current-speed characteristics for different levels of supply voltage.

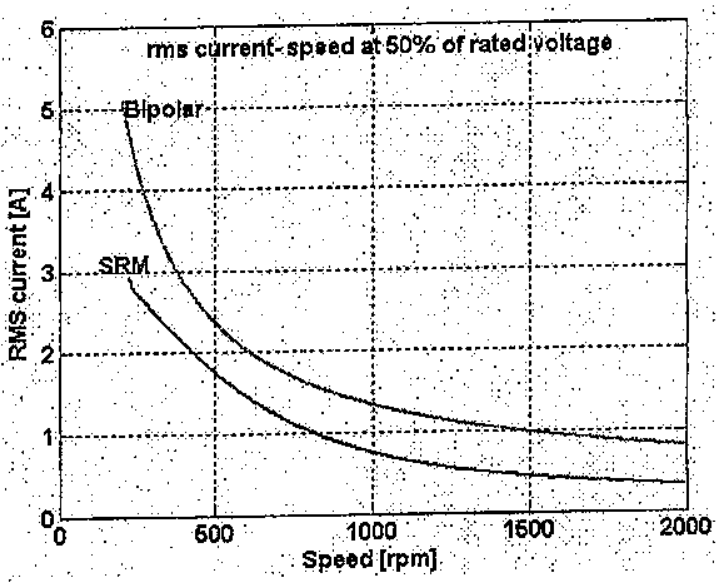

(a) At $50 \%$ of the rated voltage.

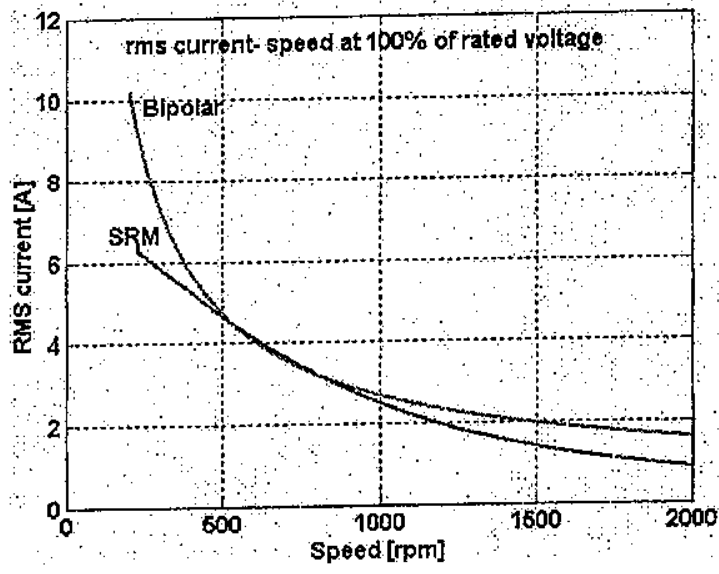

(b) At $100 \%$ of the rated voltage.

Fig. 5. Comparison of current-speed characteristics for different levels of supply voltage. 


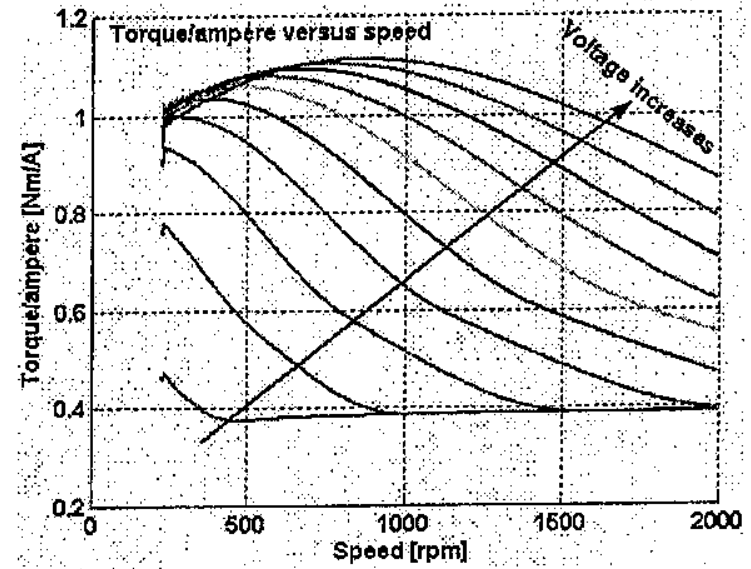

(a) Doubly-salient SRM

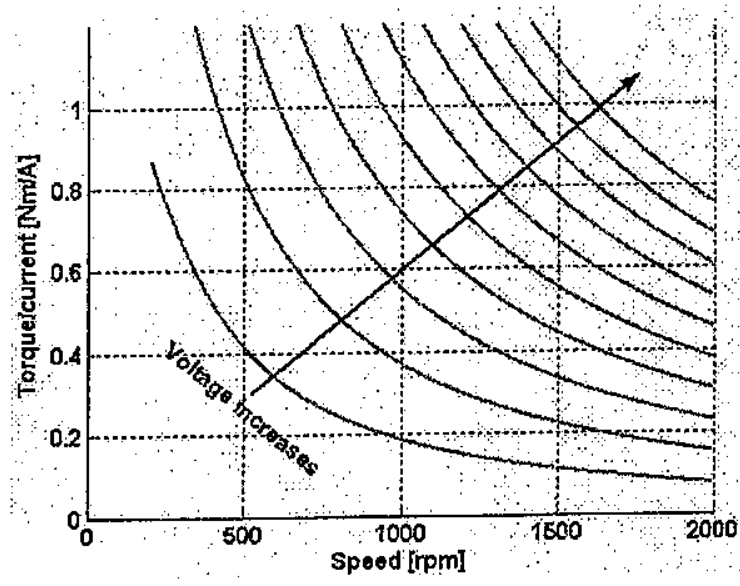

(b) FPSRM

Fig. 6. Torque per ampere characteristics for different levels of supply voltage.

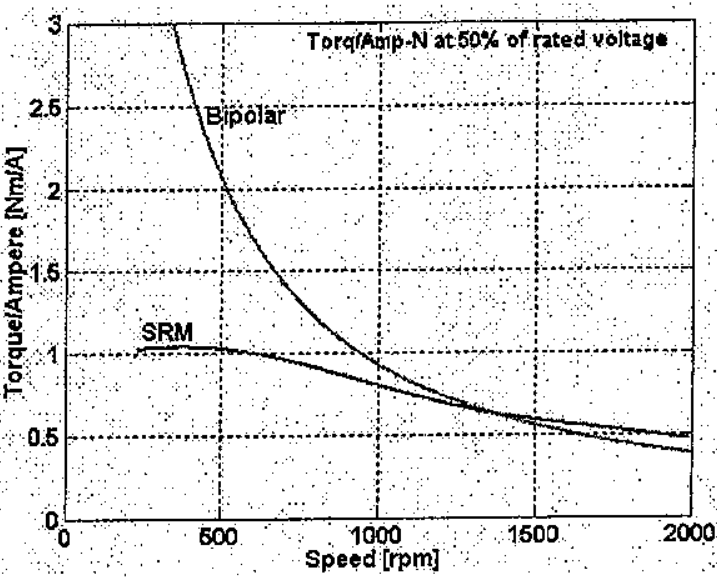

(a) At $50 \%$ of the rated voltage.

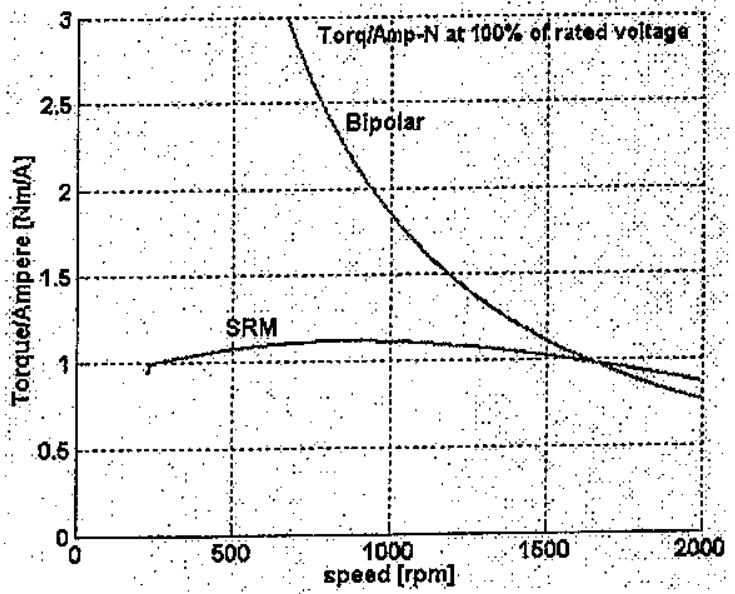

(b) At $100 \%$ of the rated voltage.

Fig. 7. Comparison of torque per ampere characteristics for different levels of supply voltage.

The input power for the two motors is predicted at different impressed voltages from $10 \%$ to $100 \%$ of the motor rating as shown in Fig. 8. Both motor types have a comparable family of power-speed curves which is characterized by high power at low speeds and low power at high speeds. The input power has a sharp variation at low speeds in bipolar motor, while in conventional one the power variation is moderate. This power variation is a direct reflection to the current drawn by the motor at each voltage level.

A comparison between the input power-speed characteristics for the two motors at $50 \%$ and $100 \%$ of their voltage rating as shown in Fig. 9. It is observed that bi-polar excited motor draws higher power at all operating speeds especially at low speed range.

The mechanical power developed by the two motor types is predicted at different impressed voltages as shown in Fig. 10. While conventional motor develops finite mechanical power increasing gradually at low speeds, bi-polar motor has a parabolic power variation with extremely high values at low speeds. A comparison between the mechanical power-speed characteristics for the two motors at $50 \%$ and $100 \%$ of their voltage rating as shown in Fig. 11. It is observed that bi-polar excited motor develops higher mechanical power at all operating speeds especially at low speed range. The higher mechanical power obtained by bi-polar excited motor is also explained by its better winding utilization. While doublyexcited motor develops successive torque stroke pulses corresponding to its phase excitation cycle, the whole windings of bi-polar motor are always excited and contribute to the developed mechanical power.

The copper losses for the two motors are predicted at different impressed voltages from $10 \%$ to $100 \%$ of the motor rating as shown in Fig. 12. Both motor types have a comparable family of copper losses 
versus speed which is characterized by high copper losses at low speeds. This variation of copper losses is due to the high current drawn at low speeds.

A comparison between copper losses for the two motors at $50 \%$ and $100 \%$ of their voltage rating as shown in Fig. 13. It is observed that bi-polar excited motor has higher losses at low speeds and the difference diminishes by increasing both the operating speed and impressed voltage. At rated voltage the copper losses are comparable and bi-polar machine has lower copper losses in the mid speed range. This copper loss variation is a direct reflection of the motor current variation.
It is well known that the conventional SRM has torque pulsation due to its winding excitation nature and doubly-salient structure. One of the essential motivations to investigate alternative motor configurations is to eliminate of at least to reduce this torque pulsation drawback. The instantaneous torque developed by the two motor types is predicted as shown in Fig. 14. It is observed that while the torque developed by conventional SRM consists of successive torque pulses, the bi-polar excited motor has almost constant torque with no variation or any pulsations. This is an advantage of the proposed motor configuration and excitation scheme.

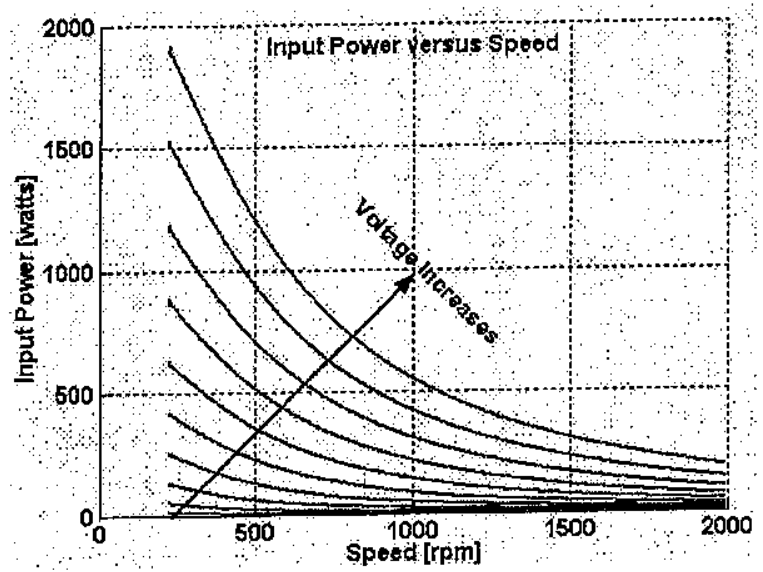

(a) Doubly-salient SRM

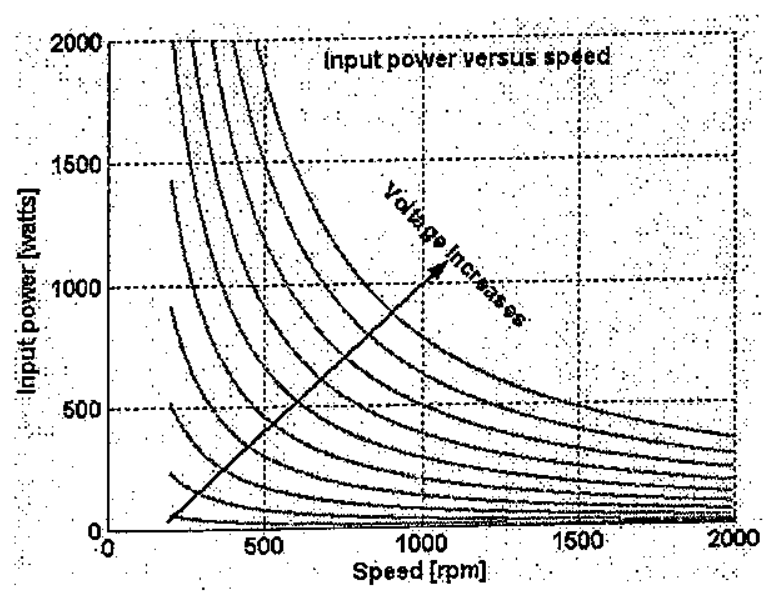

(b) FPSRM

Fig. 8. Input power for different levels of supply voltage.

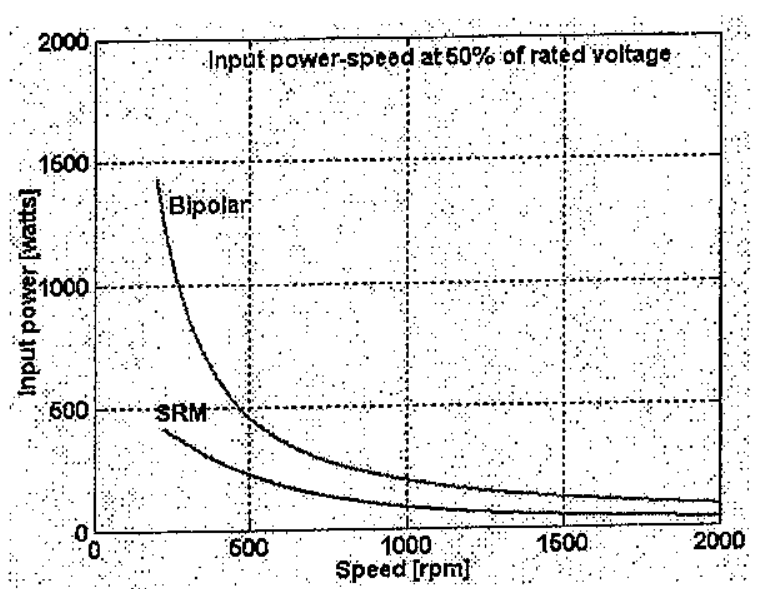

(a) At $50 \%$ of the rated voltage.

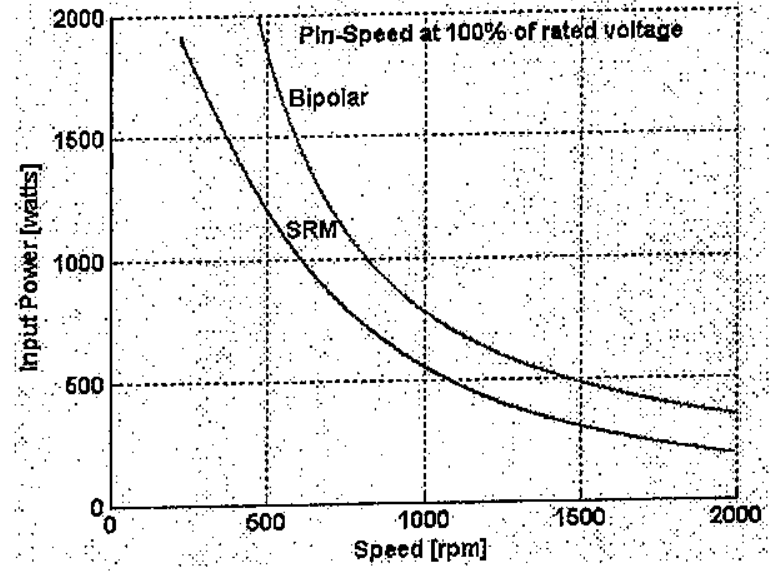

(b) At $100 \%$ of the rated voltage.

Fig. 9. Comparison of input power for different levels of supply voltage. 


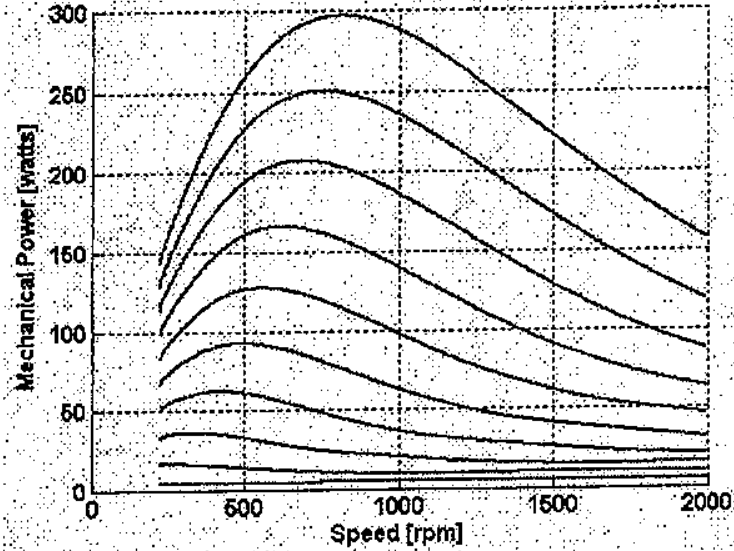

(a) Doubly-salient SRM

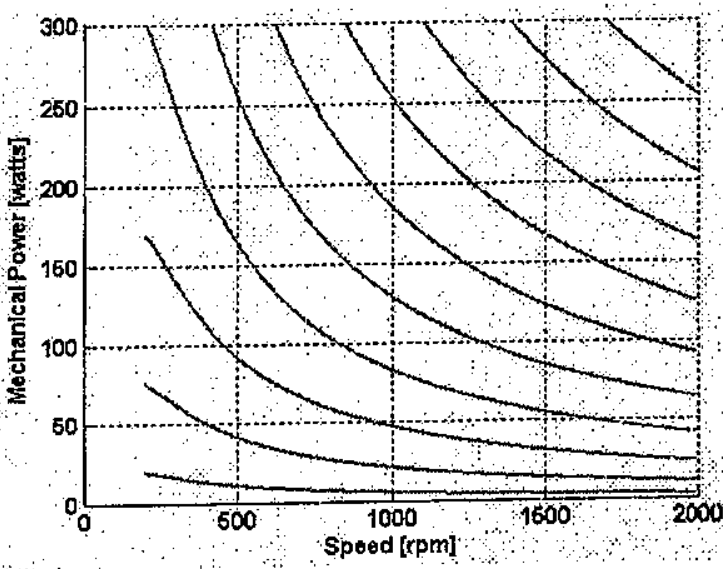

(b) FPSRM

Fig. 10. Mechanical power for different levels of supply voltage.

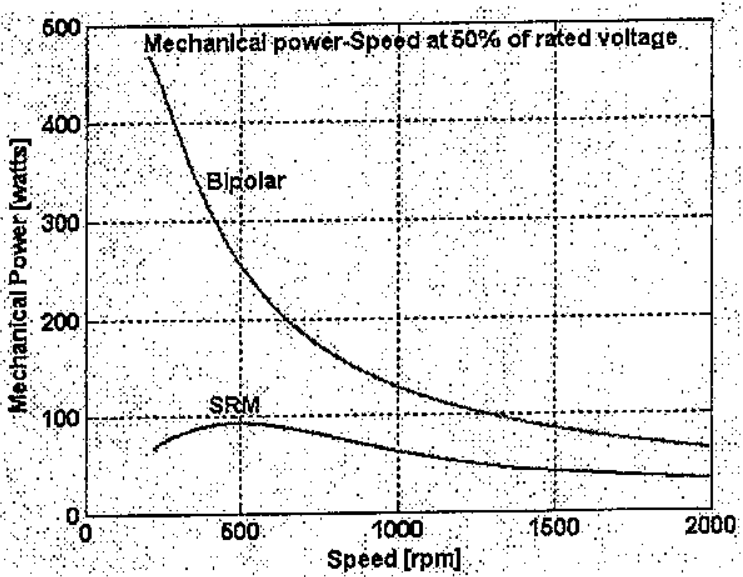

(a) At $50 \%$ of the rated voltage.

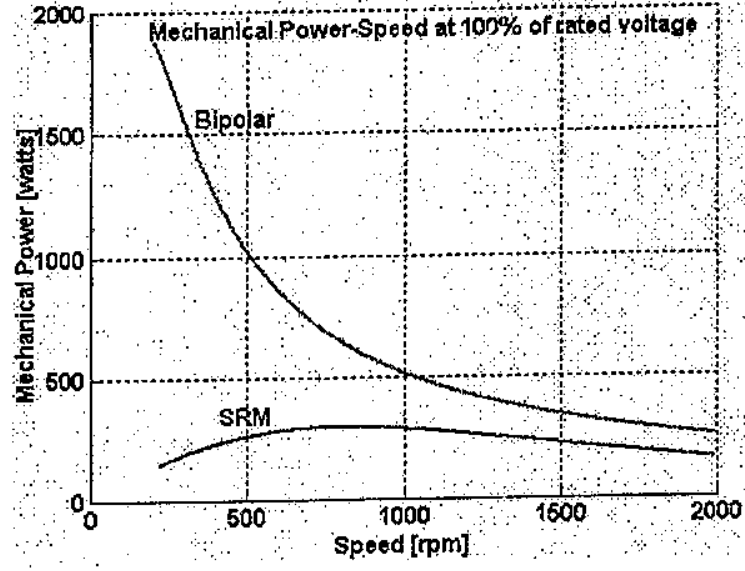

(b) At $100 \%$ of the rated voltage.

Fig. 11. Comparison of mechanical power for two different levels of supply voltage.

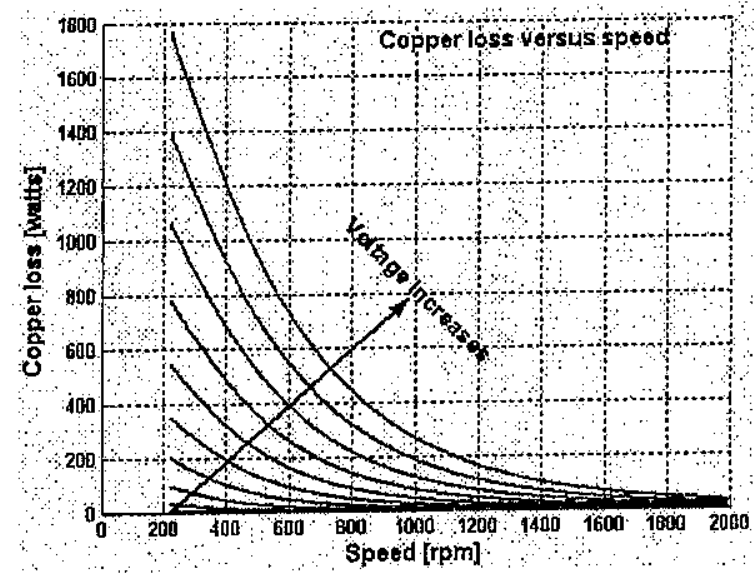

(a) Doubly-salient SRM

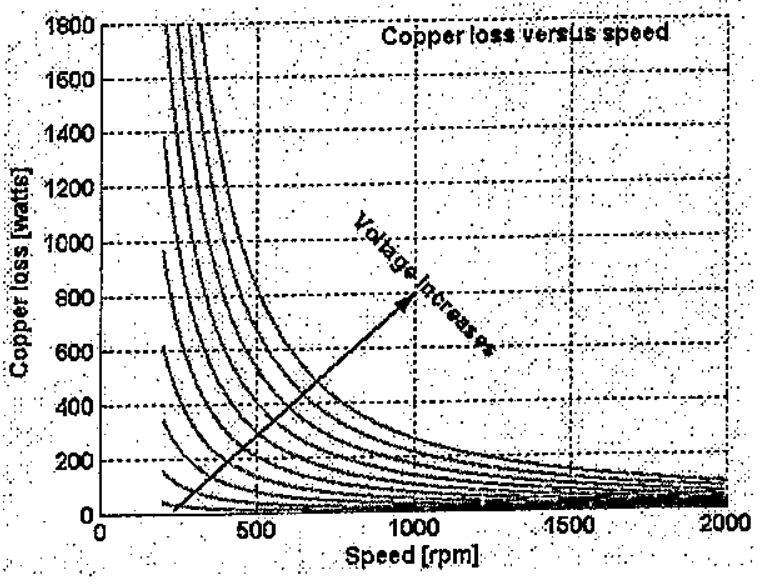

(b) FPSRM

Fig. 12. Copper loss for different levels of supply voltage. 


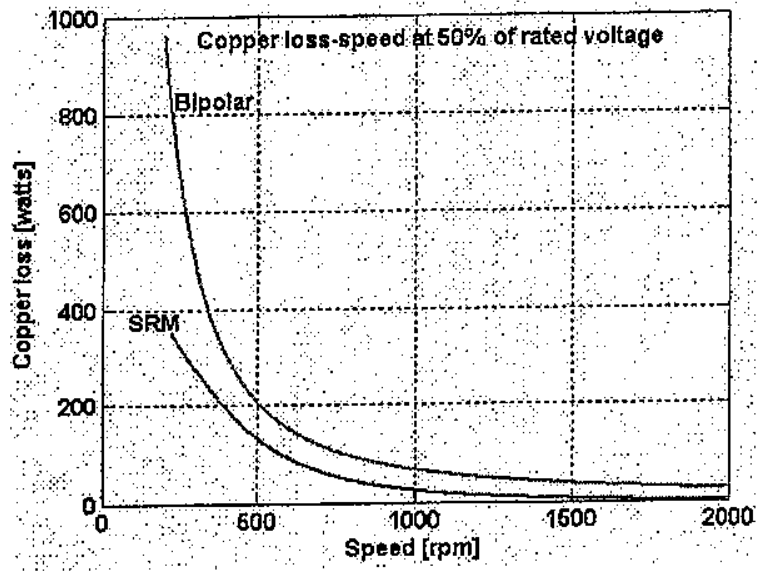

(a) At $50 \%$ of the rated voltage.

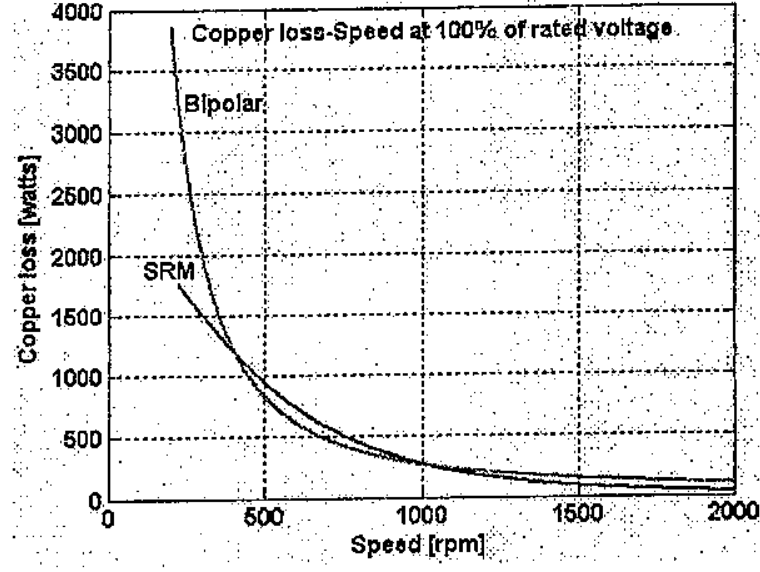

(b) At $100 \%$ of the rated voltage.

Fig. 13. Comparison of copper loss for different levels of supply voltage.

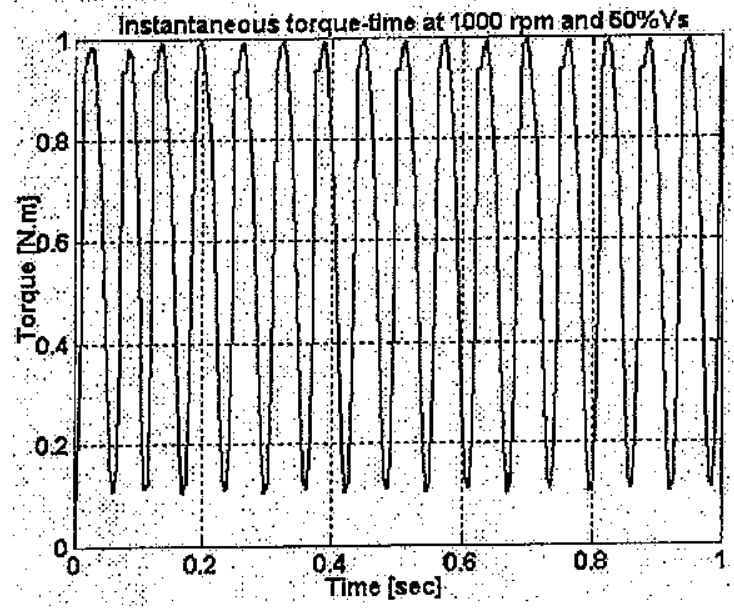

(a) Doubly-salient SRM

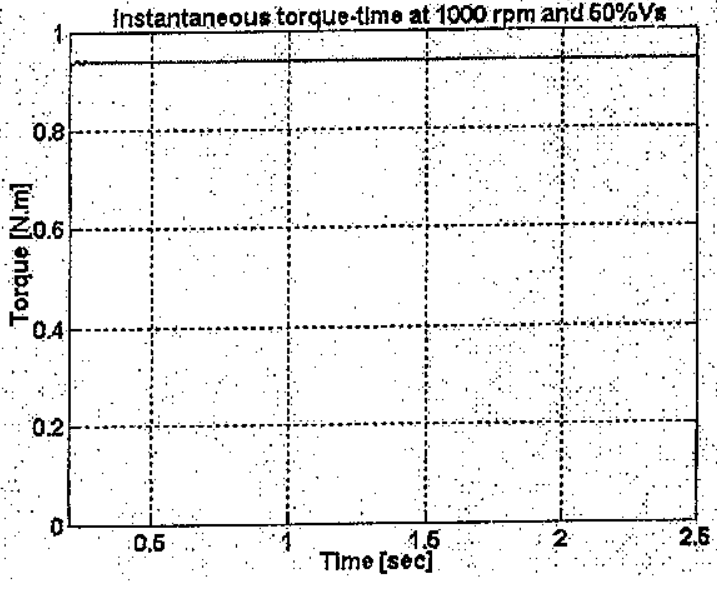

(b) FPSRM

Fig. 14. Instantaneous torque at certain speed and voltage

\section{CONCLUSION}

A variable reluctance motor with fully-pitched winding and bipolar excitation has been proposed as an alternative to conventional SRM. The proposed motor configuration has a better utilization of both magnetic and electric circuits and can be powered through a standard semiconductor power switch module. A mathematical model has been developed and investigated to evaluate its operating performance compared to its counterpart SRM. It has been found that the proposed VRM gives higher torque and better torque per current ratio at different impressed voltages at almost all operating speeds. Due to its fully-pitched distributed winding and simultaneous excitation of all phase windings, a ripple-free torque has also been achieved by the proposed motor configuration and excitation scheme.

\section{REFERENCES}

[1] P. J. Lawrenson, J. M. Stephenson, P. T. Blenkinsop, J. Corda, and N. N. Fulton, "Variable-speed switched reluctance motors", IEE Proceedings, Pt.B, Vol. 127, No. 4, July 1980, PP 253-265.

[2] B. C. Mecrow, "Fully pitched winding switched reluctance and stepping motor arrangements", IEE Proceedings, Pt-B, Vol. 140, No. 1, Jan. 1993, PP 61-70.

[3] A.C. Clothier, and B.C. Mecrow, "Inverter Topologies and Current Sensing Methods for Short Pitched and Fully Pitched Winding SR Motors", 14th Annual IEEE Applied Power Electronics Conf., Dallas, Texas, March 1999, Vol 1, PP 416-423

[4] M. M. Khater, H. Abdel-Maksoud, and S. ElDoheimy, "Performance of Three-Phase Switched Reluctance. Motors with Different 
Structures: Comparative Study", 10th International Middle East Power Systems Conference (MEPCON), 12-15 December 2005, Port Said, Egypt, PP 239-245.

[5] P. G. Barrass, B. C. Mecrow, and A. C. Clothier, "Bipolar operation of fully-pitched winding switched reluctance drives", 'Electrical Machines and Drives' IEE Conf., 11-13 September 1995, IEE Publication No. 412, PP 252-256.

[6] Zeljko Grbo, and Slobodan Vukosavic, "CostOptimized Switched Reluctance Motor Drive with Bipolar Currents", Published online, Springer-Verlag, 28 December 2005, http://www.springer-ny,com.

[7] B. C. Mecrow, A. C. Clothier, P. G. Barrass, and C. Weiner, "Drive Configurations for FullyPitched Winding Switched Reluctance Machines", Industry Applications' IEEE Conf., 12-15 Oct. 1998, Vol. 1, PP 563-570.

[8] C. Weiner, A. G. Jack, P. P. Acarnley, and B. C. Mecrow, "Flux-Linkage Control of FullyPitched Switched Reluctance Motors", European Power Electronics Conf., Lausanne, 1999, EPE'99.

[9] P. P. de Paula, W. M. da Silva , J. R. Cardoso and S. I. Nabeta, "Assessment of the Influences of the Mutual Inductances on Switched Reluctance Machines Performance", 'Electric Machines and
Drives' IEEE Conf., 1-4 June 2003, Vol. 3, PP 1732-1738.

[10] B. C. Mecrow, C. Weiner and A. C. Clothier, "The Modeling of Switched Reluctance Machines with Magnetically Coupled Windings", IEEE Transactions On Industry Applications, Vol. 37, No. 6, NOV.IDEC. 2001, PP 1675-1683

[11] B. C. Mecrow, "New winding configurations for doubly salient reluctance machines", IEEE Transactions On Industry Applications, Vol. 32, No. 6, Nov./Dec. 1996, PP 1348-1356.

[12] Y. Ozoglu, M. Garip and E. Mese, "New Pole Tip Shapes Mitigating Torque Ripple in Short Pitched and Fully Pitched Switched Reluctance Motors", 'Industry Applications' IEEE Conf., 13-18 Oct. 2002, Vol. 1, PP 43-50.

[13] HC Lovatt, ML M Clelland, and JM Stephenson, "Comparative Performance of Singly Salient Reluctance, Switched Reluctance, and Induction Motors", EMD IEE Conf., 1-3 September 1997, IEE Publication No. 444, PP 361-365.

[14] A. E. Fitzgerald and Charles Kingsley, Jr. "Electric Machinery, the Dynamics and Statics of Electromechanical Energy Conversion", Second Edition, McGraw-Hill Companies, Inc., USA, 1961 